\title{
Kendali TDS nutrisi hidroponik deep flow technique berbasis IoT menggunakan fuzzy logic
}

\author{
Annisa Nurul Sholihah ${ }^{1 *}$, Toto Tohir $^{2}$, Adnan Rafi Al Tahtawi ${ }^{3}$ \\ 1,2,3 Jurusan Teknik Elektro, Politeknik Negeri Bandung \\ Jl. Gegerkalong Hilir, Ciwaruga, Kec. Parongpong, Kabupaten Bandung Barat, Jawa Barat, Indonesia \\ 1*annisa.nurul.toi17@polban.ac.id, ${ }^{2}$ toto.tohir@ polban.ac.id, ${ }^{3}$ adnan.raf@ polban.ac.id
}

\begin{abstract}
ABSTRAK
Pada sistem hidroponik deep flow technique (DFT), setiap umur dan jenis tanaman yang ditanam memerlukan total dissolved solids (TDS) dengan satuan ppm yang berbeda serta kegagalan tanaman dalam bertumbuh dapat terjadi jika nilai TDS tidak terpantau dengan baik. Tujuan dalam penelitian ini untuk membuat sistem kendali nilai TDS dengan metode fuzzy logic agar nilai TDS sesuai dengan kondisi tanaman yang ditanam serta membuat sistem pemantau nilai TDS dengan memanfaatkan Internet of Things (IoT) agar nilai TDS dapat terpantau dengan baik. Sistem ini menggunakan nilai error dan delta error yang didapat dari selisih nilai setpoint dengan sensor TDS SKU:SEN0244 sebagai masukan fuzzy logic. Keluaran sistem berupa durasi ON dan OFF relay yang terhubung dengan pompa air 12 VDC. Nilai setpoint dan bacaan sensor akan ditampilkan pada LCD serta ditampilkan juga pada aplikasi Android Blynk dengan menggunakan module WiFi NodeMCU ESP8266 sebagai wireless. Hasil pengujian dari sistem yang dirancang yaitu sensor TDS yang digunakan memiliki rata-rata error sebesar $0,165 \%$. Pengendalian yang dirancang mampu menghasilkan nilai integral absolute error (IAE) terkecil sebesar 1119 pada setpoint $800 \mathrm{ppm}$ dan integral time absolute error (ITAE) terkecil sebesar 4200 pada setpoint 1000 ppm.
\end{abstract}

Kata kunci: hidroponik DFT, TDS, fuzzy logic, Internet of Things

\section{ABSTRACT}

In the deep flow technique (DFT) hydroponic system, each age and type of plant planted requires different total dissolved solids (TDS) and plant failure to grow can occur if the TDS value is not monitored properly. The purpose of this study is to create a TDS value control system with the fuzzy logic method so that the TDS value is in accordance with the conditions of the plants being planted and to create a TDS value monitoring system by utilizing the Internet of Things (IoT) so that the TDS value can be monitored properly. This system uses the error value and delta error obtained from the difference in the setpoint value with the TDS sensor SKU:SENO244 as fuzzy logic input. The output of the system is the duration of ON and OFF relay which is connected to a 12 VDC water pump. The setpoint value and sensor readings will be displayed on the LCD and also displayed on the Blynk Android application using the NodeMCU ESP8266 WiFi module as wireless. The test results of the designed system, namely the TDS sensor used has an average error of $0.165 \%$. The control designed is able to produce the smallest integral absolute error (IAE) of 1119 at the setpoint of 800 ppm and the smallest integral time absolute error (ITAE) of 4200 at the setpoint of $1000 \mathrm{ppm}$.

Keywords: DFT hydroponic, TDS, fuzzy logic, Internet of Things

\section{PENDAHULUAN}

Hidroponik adalah lahan budidaya pertanian dengan menggunakan air sebagai medium untuk menggantikan tanah, sehingga sistem bercocok tanam secara hidroponik dapat memanfaatkan lahan yang sempit [1]. Hidroponik memiliki beberapa macam sistem, salah satu sistem yang sudah banyak digunakan adalah sistem deep flow technique (DFT). Sistem DFT merupakan sistem yang menggunakan genangan larutan nutrisi dengan tinggi sekitar 3-4 cm sehingga akar tanaman selalu terendam di dalam larutan nutrisi [2]. Pada sistem hidroponik diperlukan kepekatan nutrisi atau total dissolved solids (TDS) dengan satuan ppm tertentu agar tanaman dapat tumbuh dengan baik. Setiap jenis dan umur tanaman membutuhkan jumlah ppm yang berbeda. Nilai TDS yang tidak terpantau dengan baik akan menyebabkan tanaman yang ditanam dalam hidroponik DFT mengalami kegagalan 
dalam bertumbuh, sehingga sistem Internet of Things (IoT) dapat dimanfaatkan untuk mempermudah dalam memonitoring nilai TDS pada hidroponik.

Sistem untuk mengontrol larutan nutrisi pada hidroponik sudah banyak dikembangkan seperti mengatur kadar $\mathrm{pH}$ hidroponik dan mengatur TDS hidroponik dengan menggunakan berbagai metode pengendalian seperti proportional integral derivative (PID) pada penelitian [3]-[5] dan fuzzy logic controller (FLC) pada penelitian [6]-[12]. Metode PID banyak digunakan karena kesederhanaannya dalam hal implementasi pemrograman, namun dalam perancangannya setidaknya dibutuhkan respon loop terbuka dari plant yang akan dikendalikan, serta diperlukan metode penalaan konstanta yang optimal. Sebaliknya, metode FLC lebih rumit untuk diimplementasikan ke dalam bahasa pemrograman, namun dalam perancangannya lebih sederhana karena hanya mengandalkan logika dan tidak diperlukan model matematis dari plant yang akan dikendalikan.

Penelitian ini bertujuan untuk merancang dan mengimplementasikan pengendalian nilai TDS berbasis IoT pada hidroponik sistem DFT menggunakan metode fuzzy logic. Lebih khusus lagi penelitian ini dilakukan agar nilai TDS sesuai dengan kebutuhan tanaman yang ditanam dan nilai TDS dapat dipantau dengan jarak jauh melalui jaringan internet. Pada penelitian ini metode yang digunakan sama seperti penelitian [7] yang memanfaatkan nilai error dan delta error sebagai masukan fuzzy logic serta penggunaan sistem IoT untuk memantau nilai dari parameter yang diukur. Perbedaannya pada penelitian ini parameter yang dikendalikan adalah TDS seperti halnya pada penelitian [11]. Lingkup dari penelitian ini dibatasi yaitu sistem hidroponik yang dipakai adalah sistem DFT dengan parameter yang dikendalikan berupa nilai TDS dan menggunakan metode fuzzy logic tipe Sugeno. Arduino Mega 2560 digunakan sebagai mikrokontroler dan Module WiFi NodeMCU ESP8266 sebagai modul wireless.

\section{METODE PENELITIAN}

\subsection{Perancangan Hidroponik Deep Flow Technique (DFT)}

Hidroponik DFT yang dirancang menggunakan sistem A Frame, dengan 8 gully yang masing masing gully terdapat 6 lubang pot dengan jarak satu lubang pot dengan lubang pot yang lain $15 \mathrm{~cm}$. Tinggi hidroponik yang dirancang $200 \mathrm{~cm}$ dengan lebar $211 \mathrm{~cm}$ dan penampung nutrisi yang memiliki ukuran $123 \mathrm{~cm}$ x $123 \mathrm{~cm}$ x $46 \mathrm{~cm}$. Sistem kendali yang dirancang akan ditempatkan pada sisi depan penampung nutrisi (berseberangan dengan hidroponik). Rancangan dapat dilihat pada Gambar 1.

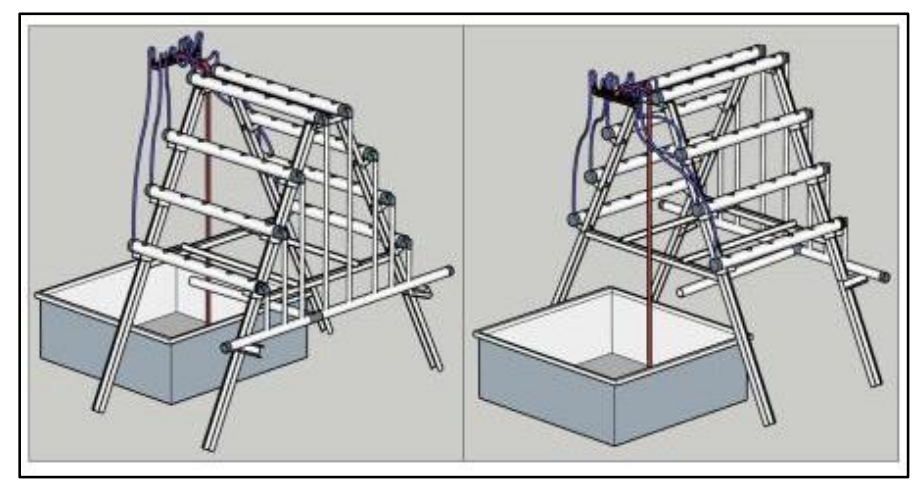

Gambar 1. Rancangan hidroponik DFT

\subsection{Fuzzy Logic Control (FLC)}

FLC digunakan untuk menjaga nilai TDS pada nutrisi hidroponik agar sesuai dengan setpoint atau toleransi. Diagram blok pengendalian nilai TDS dapat dilihat pada Gambar 2. Masukan yang digunakan adalah error dan delta error dengan persamaan berikut.

$$
\begin{gathered}
\operatorname{error}(t)=\text { setpoint }- \text { output } \\
\operatorname{derror}(t)=\operatorname{error}(t)-\operatorname{error}(t-1)
\end{gathered}
$$

dimana error (t) adalah nilai error, derror (t) adalah nilai perubahan error, dan error (t-1) adalah nilai error sebelumnya. Hasil yang didapat dari pengolahan FLC akan menentukan kondisi masing-masing 
relay yang terhubung ke pompa air. Keluaran yang dihasilkan akan dibaca oleh sensor TDS lalu diolah kembali hingga nilai TDS yang diukur sesuai dengan nilai setpoint atau toleransi.

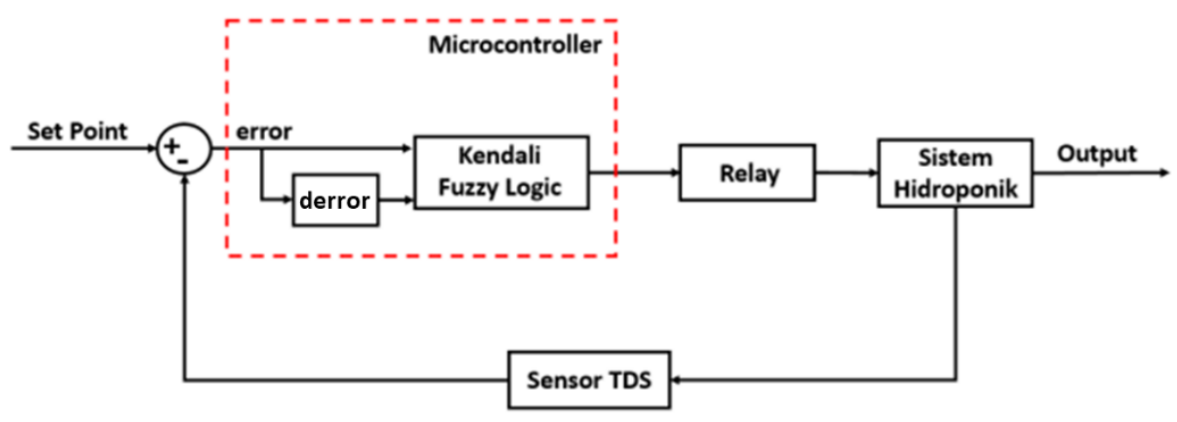

Gambar 2. Diagram blok pengendalian nilai TDS

Untuk membuat sistem FLC diperlukan fungsi keanggotaan untuk setiap variabel masukan dan keluaran. Fungsi keanggotaan masukan error pada Gambar 3 menggunakan 5 himpunan dengan rentang -1 sampai 4. Fungsi keanggotaan error diantaranya adalah Error Negative (EN), Error Zero (EZ), Error Positive Rendah (EPR), Error Positive Sedang (EPS), dan Error Positive Tinggi (EPT).

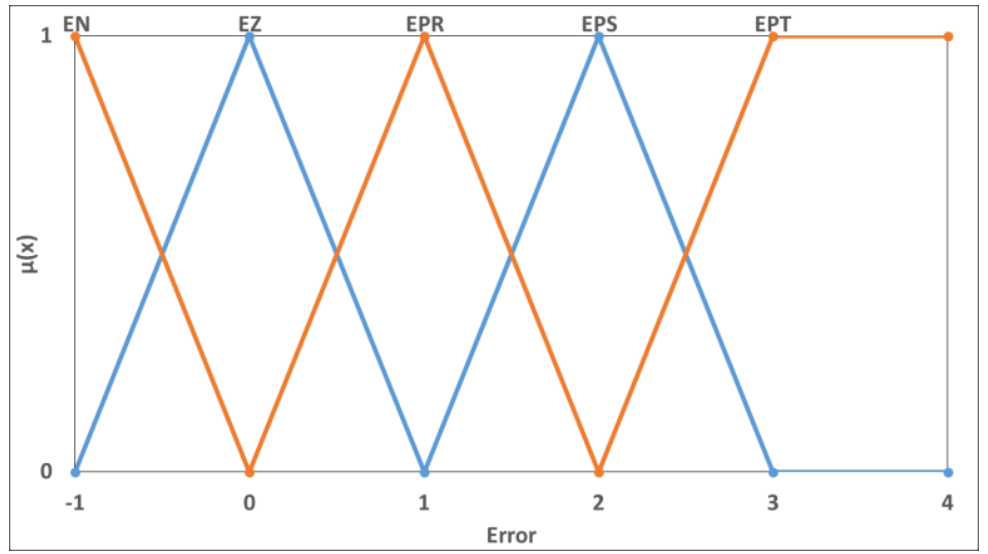

Gambar 3. Fungsi keanggotaan error

Sementara fungsi keanggotaan input delta error pada Gambar 4 menggunakan 3 himpunan dengan rentang -2 sampai 2. Fungsi keanggotaan delta error diantaranya adalah Delta Error Negative (dEN), Delta Error Zero (dEZ) dan Delta Error Positive (dEP).

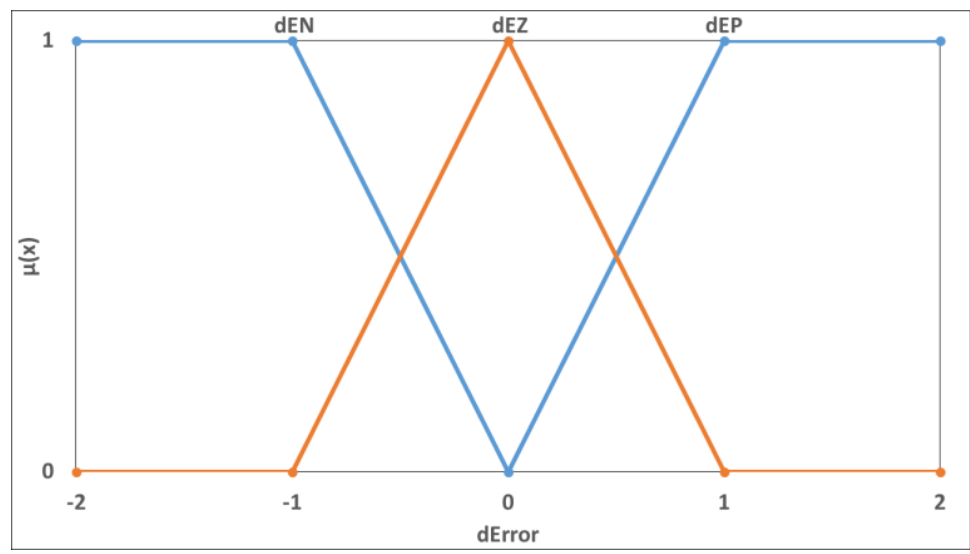

Gambar 4. Fungsi keanggotaan delta error

Fungsi keanggotaan keluaran relay pada Gambar 5 menggunakan 4 himpunan dengan nilai yang berbeda diantaranya yaitu OFF dengan nilai 100, ON Sebentar (ONSB) dengan nilai 200, ON Sedang 
(ONS) dengan nilai 400, dan ON Lama (ONL) dengan nilai 600. Jika defuzzifikasi menghasilkan nilai $\leq 100$ maka relay akan OFF dan jika defuzzifikasi menghasilkan nilai $\geq 100$ relay akan ON dengan durasi sesuai nilai defuzzifikasi.

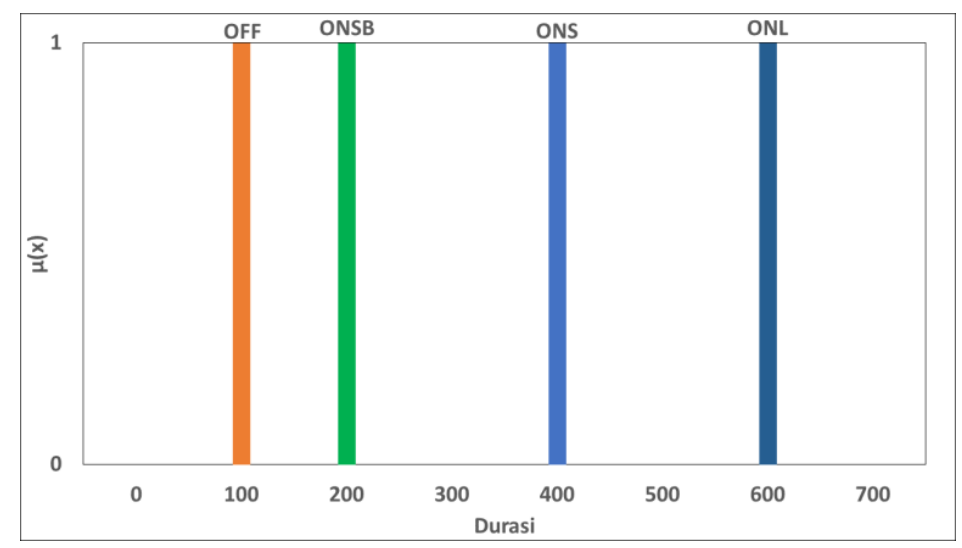

Gambar 5. Fungsi keanggotaan durasi relay

Setelah membuat fungsi keanggotaan kemudian dibuat rule base dengan menggunakan if-then. Cara kerja rule base yang digunakan pada nilai error adalah saat error yang dihasilkan Error Negative (EN) maka hasil bacaan sensor lebih besar dari setpoint, saat error yang dihasilkan Error Zero (EZ) maka hasil bacaan sensor sama dengan setpoint dan saat error yang dihasilkan Error Positive maka hasil bacaan sensor lebih kecil dari setpoint. Yang membedakan antara Error Posistive Rendah (EPR), Error Positive Sedang (EPS), dan Error Positive Tinggi (EPT) adalah besar nilai error yang terbaca. Cara kerja rule base yang digunakan pada nilai delta error adalah jika Delta Error Negative (dEN) maka perubahan delta error akan naik, jika Delta Error Zero (dEZ) maka perubahan error konstan, dan jika Delta Error Positive (dEP) maka perubahan error turun. Rule base yang digunakan dapat dilihat pada Tabel 1. Pada Tabel 1 terdapat 15 kemungkinan, 8 kemungkinan OFF, 3 kemungkinan ON Sebentar (ONSB), 2 kemungkinan ON Sedang (ONS), dan 2 kemungkinan ON Lama (ONL).

Tabel 1. Rule Base

\begin{tabular}{|c|c|c|c|}
\hline Error $d$ dError & dEN & dEZ & dEP \\
\hline EN & OFF & OFF & OFF \\
\hline $\mathbf{E Z}$ & OFF & OFF & ONSB \\
\hline EPR & OFF & ONSB & ONSB \\
\hline EPS & OFF & ONS & ONS \\
\hline EPT & OFF & $\mathrm{ONL}$ & ONL \\
\hline
\end{tabular}

Tahap akhir adalah defuzzifikasi dimana variabel fuzzy yang diolah diubah kembali menjadi nilai tegas atau nilai crisp dengan menggunakan persamaan yang dapat dilihat pada persamaan Weighted Average seperti berikut.

$$
Z_{\text {out }}=\frac{\sum_{i=1}^{n} w_{i} z_{i}}{\sum_{i=1}^{n} w_{i}}
$$

dimana $Z_{\text {out }}$ adalah nilai keluaran crisp, $w_{i}$ adalah derajat keanggotaan nilai ke-i dan $z_{i}$ adalah nilai keluaran variable ke-i.

\subsection{Perancangan Perangkat Keras}

Diagram blok sistem dapat dilihat pada Gambar 6 dan rangkaian dari perangkat keras dapat dilihat pada Gambar 7. LCD keypad shield page 1 digunakan untuk mengatur setpoint dan page 2 digunakan untuk menampilkan nilai sensor TDS. Nilai setpoint dan sensor TDS dikirim ke Arduino Mega 2560 untuk dihitung nilai error dan delta error yang akan dijadikan sebagai masukan FLC yang sudah terprogram dalam Arduino Mega 2560. Keluaran Arduino Mega 2560 akan mengendalikan durasi ON dan OFF relay yang sudah terhubung dengan pompa 12 VDC. Nilai setpoint dan sensor 
TDS yang ada pada Arduino juga dikirim pada NodeMCU sehingga kedua nilai tersebut dapat ditampilkan pada aplikasi Android Blynk melalui jaringan internet.

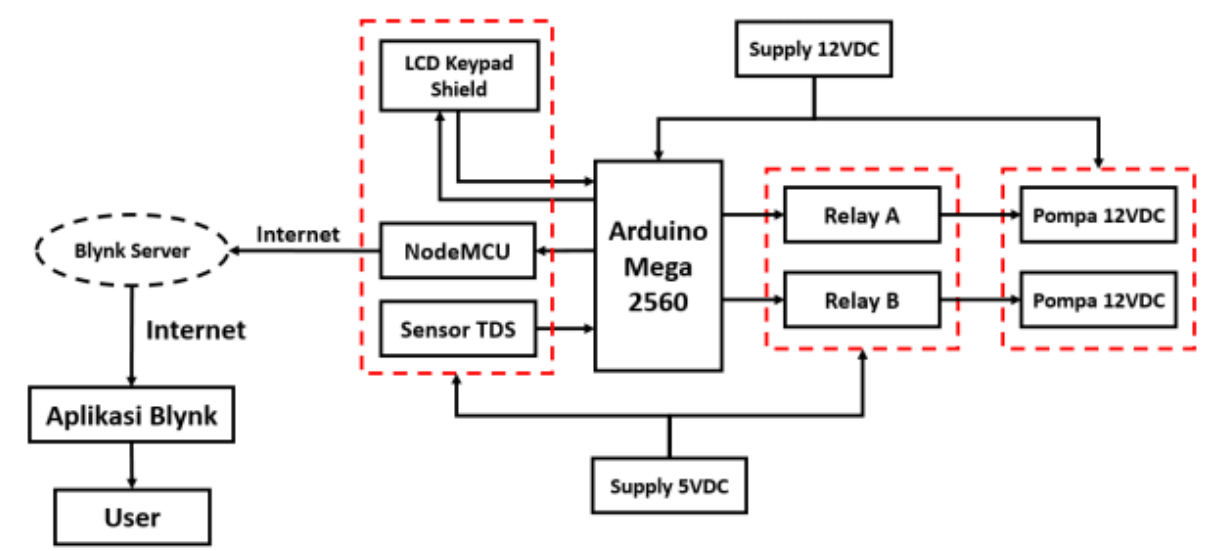

Gambar 6. Diagram blok sistem

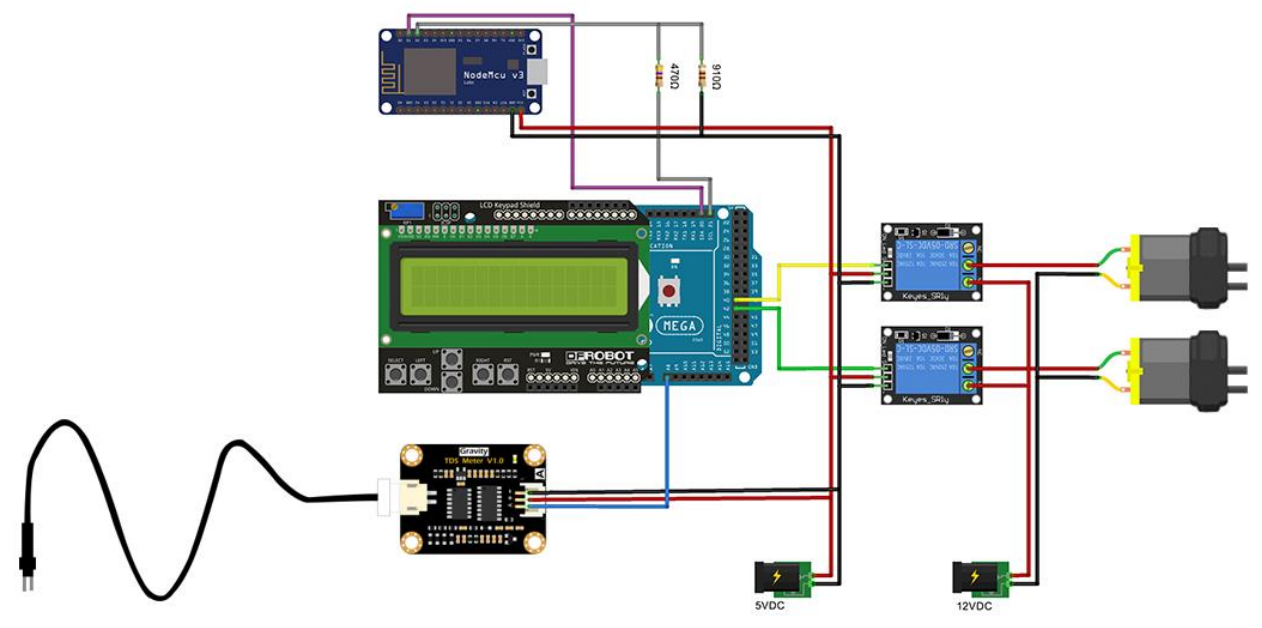

Gambar 7. Rangkaian perangkat keras

\subsection{Perancangan Sistem IoT}

Sistem IoT yang akan digunakan untuk memantau nilai TDS menggunakan aplikasi Android Blynk. Pembuatan sistem IoT dengan aplikasi Blynk hanya perlu melakukan dragging dan dropping widget yang sudah disediakan dalam aplikasi dan setiap widget dapat diatur sesuai dengan kebutuhan. Perancangan sistem IoT pada aplikasi Blynk hanya menggunakan 3 widget yaitu 2 gauge untuk melihat nilai setpoint dan sensor TDS, lalu 1 SuperChart untuk menampilkan grafik nilai setpoint dan sensor TDS. Perancangan dapat dilihat pada Gambar 8. Untuk menghubungkan aplikasi Blynk dengan perangkat keras perlu memasukan AuthToken yang diberikan oleh pihak Blynk pada program Arduino IDE.
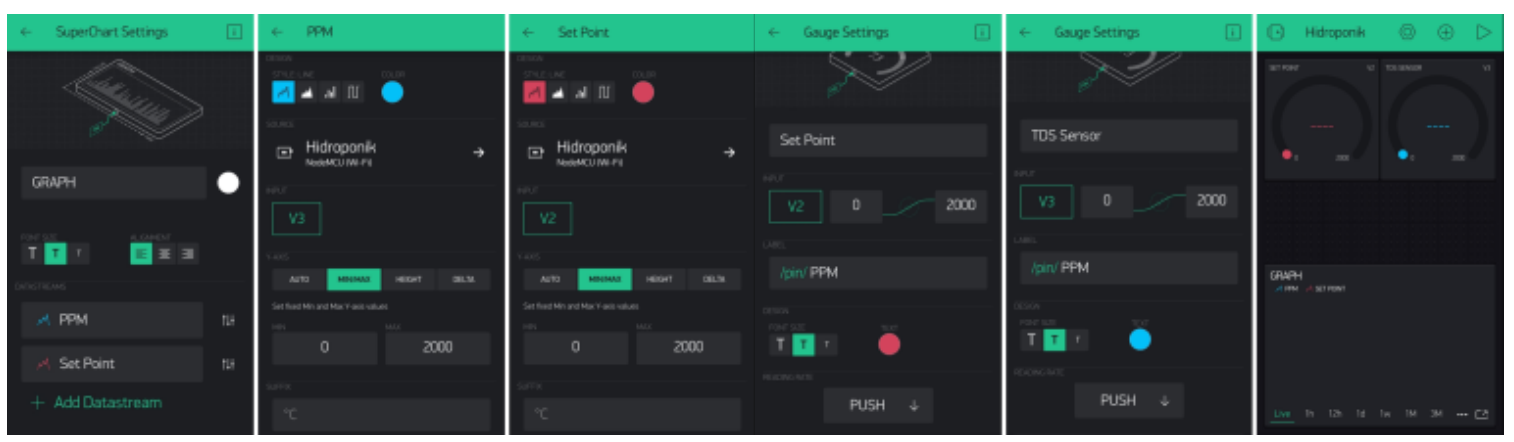

Gambar 8. Perancangan sistem IoT pada aplikasi Blynk 


\section{HASIL DAN PEMBAHASAN}

\subsection{Implementasi Sistem}

Hasil dari pembuatan perangkat keras dapat dilihat pada Gambar 9. Perangkat keras dibentuk menggunakan box panel berukuran $19 \mathrm{~cm}$ x $29 \mathrm{~cm}$ x $140 \mathrm{~cm}$ yang di dalamnya terdapat rangkaian power supply, masukan, pengendali, modul WiFi, dan keluaran. Untuk menyalakan alat secara keseluruhan perlu menghubungkan dua sumber pada tegangan $220 \mathrm{~V}$.

Cara kerja sistem yang sudah dibuat yaitu setpoint diatur pada page 1 LCD keypad shield dan kondisi relay tidak bekerja, lalu page dipindah ke page 2 yang menampilkan nilai bacaan sensor TDS dan kondisi relay bekerja. Jika nilai TDS kurang dari (setpoint - 50) relay akan ON dengan lama sesuai hasil defuzzifikasi lalu OFF selama $30 \mathrm{~s}$ dan akan ON kembali jika nilai TDS yang terukur tetap kurang dari (setpoint - 50). Proses tersebut akan terus terulang hingga nilai TDS yang terukur mencapai nilai (setpoint - 50) atau lebih. Setiap relay terhubung dengan satu pompa 12 VDC. Nilai setpoint dan sensor akan ditampilkan pada LCD dan aplikasi Android Blynk.

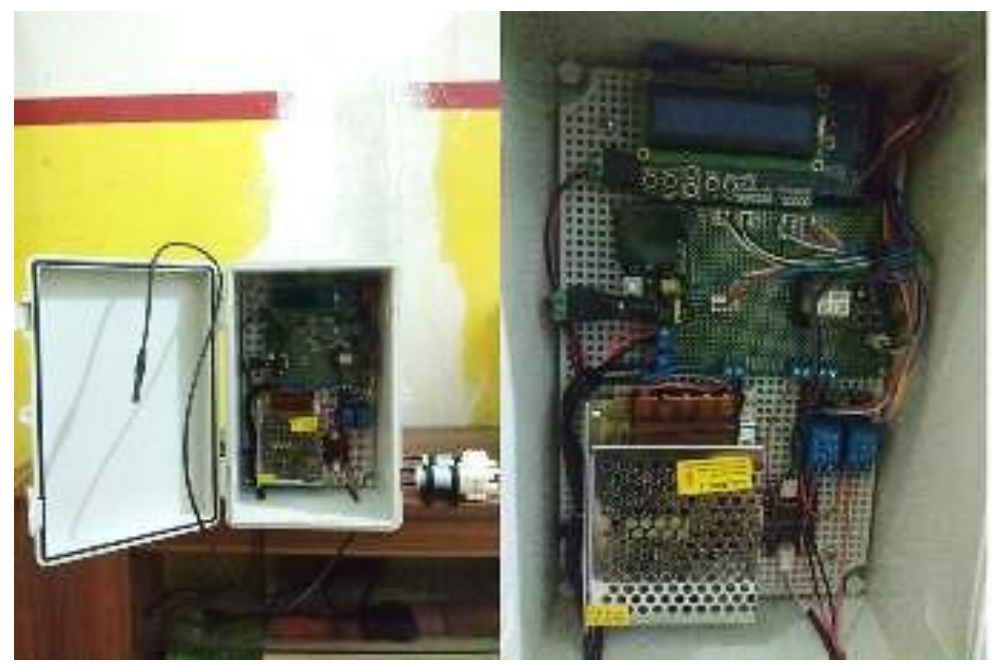

Gambar 9. Implementasi perangkat keras

Lalu nilai setpoint dan nilai sensor TDS akan ditampilkan pada aplikasi Android Blynk yang sudah dibuat untuk sistem monitoring. Sistem akan bekerja saat alat terhubung dengan WiFi dan Android yang digunakan terhubung dengan jaringan internet. Warna merah menunjukan nilai setpoint dan yang berwarna biru menunjukan nilai bacaan sensor. Tampilan hasil desain sistem monitoring pada aplikasi Blynk dapat dilihat pada Gambar 10. Fitur grafik pada aplikasi Blynk dapat dipindah menjadi landscape full screen seperti yang terlihat pada Gambar 10 disisi kanan.

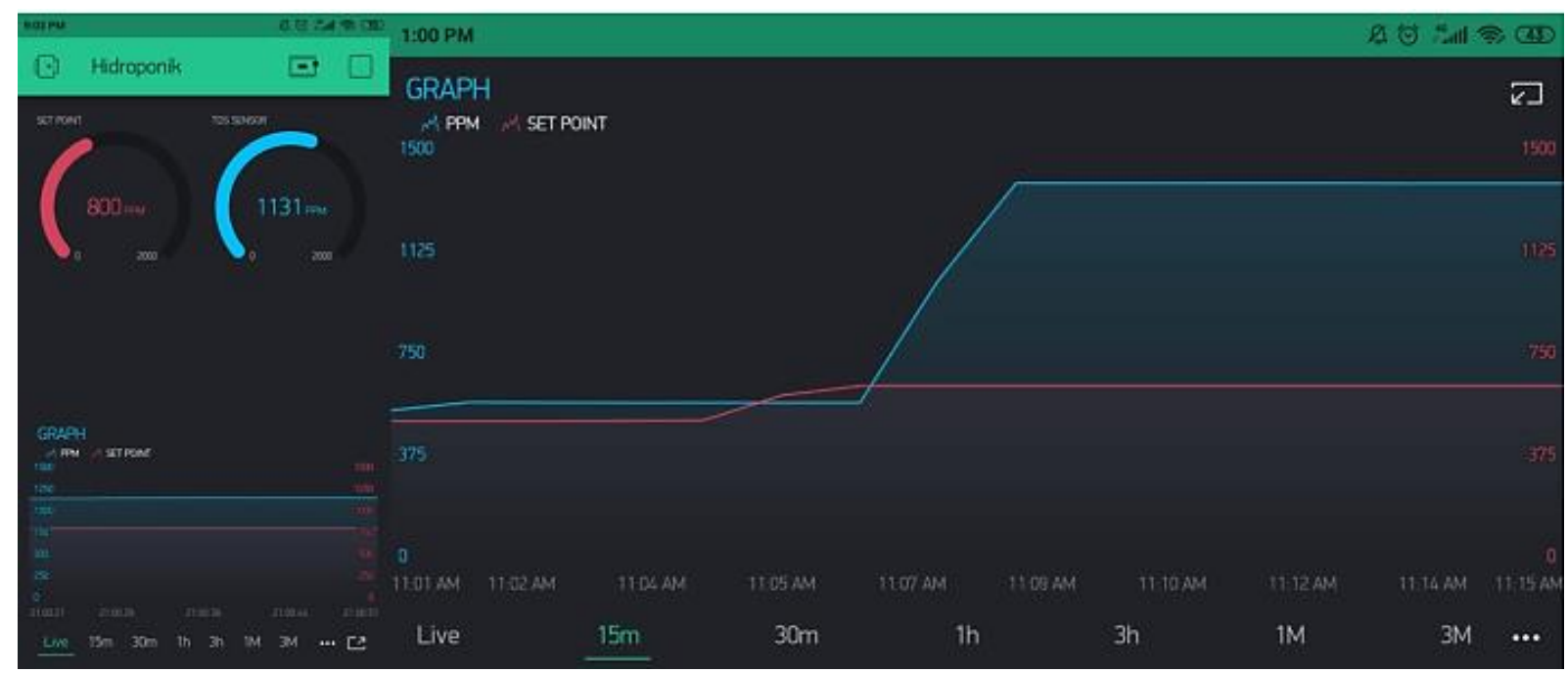

Gambar 10. Implementasi sistem IoT 


\subsection{Pengujian Sensor}

Pengujian sensor TDS dilakukan untuk melihat akurasi dari sensor yang digunakan. Pengujian sensor TDS dilakukan dengan cara membandingkan hasil pengukuran sensor TDS dengan TDS meter. Lima jenis cairan digunakan untuk menguji sensor TDS. Hasil dari pengujian bisa dilihat pada Tabel 2. Untuk mengetahui persentase error digunakan persamaan sebagai berikut.

$$
\% \text { error }=\frac{(\text { dataSensor }- \text { dataMeter })}{(\text { dataMeter })} \times 100 \%
$$

Tabel 2. Hasil pengujian sensor TDS

\begin{tabular}{|c|c|c|c|}
\hline Jenis Cairan & Sensor TDS (ppm) & TDS Meter (ppm) & Error (\%) \\
\hline Air mineral & 177 & 177 & 0 \\
\hline Susu & 818 & 820 & 0,24 \\
\hline Sirup & 848 & 849 & 0,117 \\
\hline Air keran & 721 & 723 & 0,276 \\
\hline Air sabun & 1034 & 1036 & 0,193 \\
\hline \multicolumn{3}{|c|}{ Rata-rata } \\
\hline
\end{tabular}

Dari hasil pengujian sensor TDS dapat dilihat rata-rata persentase error adalah $0,165 \%$, nilai error terbesar terdapat pada air keran dengan persentase error sebesar $0,276 \%$, dan nilai error terkecil terdapat pada air mineral sebesar $0 \%$.

\subsection{Pengujian FLC}

Pengujian ini dilakukan untuk melihat bagaimana respon grafik saat kandungan TDS pada air nutrisi dikendalikan dengan alat yang sudah dibuat. Hasil dari pengujian dapat dilihat pada Gambar 11 dimana nilai sensor berada dalam area nilai toleransi $50 \mathrm{ppm}$ mendekati nilai setpoint.

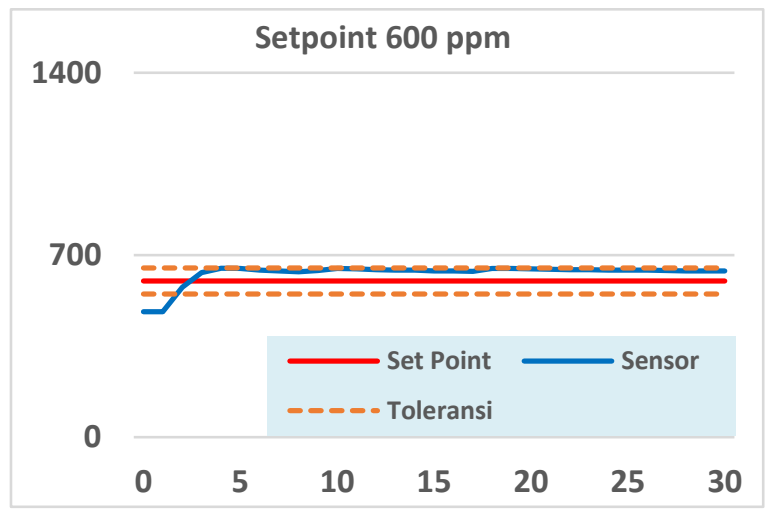

(a)

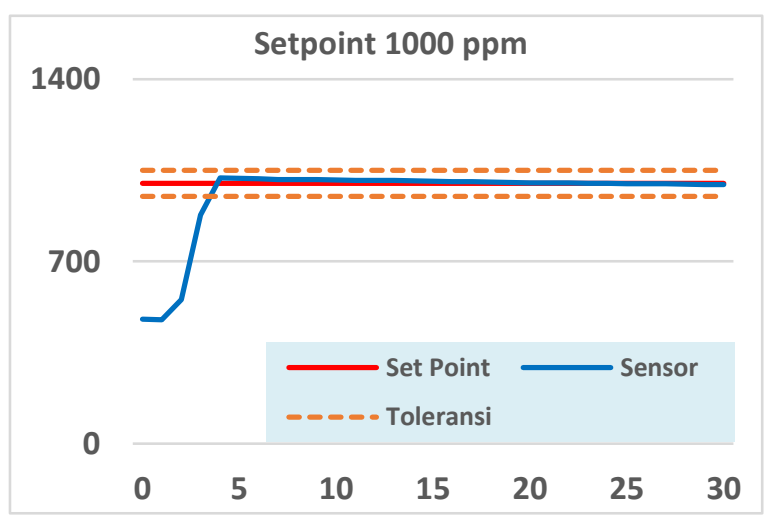

(c)

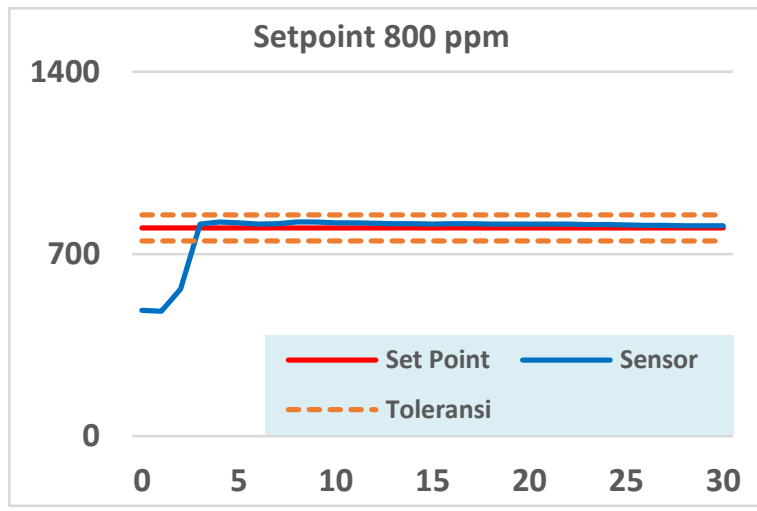

(b)

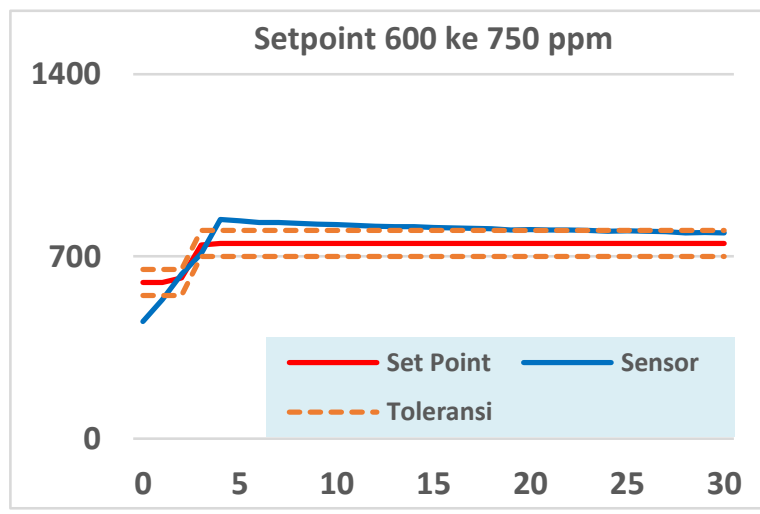

(d)

Gambar 11. Pengujian pengendalian: (a) setpoint 600 ppm, (b) setpoint 800 ppm, (c) setpoint 1000 ppm, (d) setpoint 600 ppm ke 700 ppm 
Untuk membandingkan hasil dari percobaan dilakukan analisis integral error dengan menggunakan Integral Absolute Error (IAE) dan Integral Time Absolute Error (ITAE) dengan persamaan sebagai berikut:

$$
\begin{aligned}
I A E & =\int_{0}^{\infty}|e(t)| d t \\
I T A E & =\int_{0}^{\infty} t|e(t)| d t
\end{aligned}
$$

Tabel 3. Nilai IAE dan ITAE

\begin{tabular}{|l|c|c|}
\hline \multicolumn{1}{|c|}{ Setpoint } & IAE & ITAE \\
\hline $600 \mathrm{ppm}$ & 1341 & $1,882 \times 10^{4}$ \\
\hline $800 \mathrm{ppm}$ & 1119 & 6894 \\
\hline $1000 \mathrm{ppm}$ & 1547 & 4200 \\
\hline $600 \mathrm{ke} 750 \mathrm{ppm}$ & 1755 & $2,431 \times 10^{4}$ \\
\hline
\end{tabular}

Berdasarkan hasil pengujian diperoleh bahwa nilai IAE terkecil diperoleh pada setpoint $800 \mathrm{ppm}$ dengan nilai 1119, sedangkan nilai IAE terbesar diperoleh pada setpoint berubah dari $600 \mathrm{ppm}$ ke 750 ppm. Sementara nilai ITAE terkecil diperoleh pada pengujian dengan setpoint $1000 \mathrm{ppm}$, sedangkan nilai ITAE terbesar diperoleh pada pengujian dengan setpoint berubah dari $600 \mathrm{ppm}$ ke $750 \mathrm{ppm}$. Dari hasil tersebut dapat dilihat bahwa FLC belum dapat sepenuhnya mengeliminasi error steady state. Namun demikian, FLC mampu menghasilkan nilai TDS berada pada rentang nilai yang diizinkan untuk setiap nilai TDS.

\section{KESIMPULAN}

Sistem kendali TDS untuk hidroponik DFT dengan FLC berbasis IoT berhasil dirancang dan diimplementasikan. FLC dirancang menggunakan error dan delta error sebagai masukan dan durasi relay ON dan OFF sebagai keluaran. Aplikasi Blynk pada Android juga berhasil dirancang sebagai sistem monitoring. Hasil dari pengujian sistem yaitu nilai rata-rata error dari sensor TDS sebesar 0,165\%. Pengujian pengendalian menunjukkan bahwa FLC mampu menghasilkan nilai TDS sesuai dengan setpoint yang ditetapkan dengan nilai error terkecil yaitu pada setpoint 800 ppm dan nilai error terbesar pada saat setpoint berubah dari $600 \mathrm{ke} 750 \mathrm{ppm}$. Saran untuk penelitian selanjutnya yaitu menambahkan skema kendali seperti integral yang mampu mengeliminasi error steady state.

\section{UCAPAN TERIMA KASIH}

Tim peneliti mengucapkan terimakasih kepada Politeknik Negeri Bandung, melalui wakil Direktur Akademik atas bantuan pendanaan penyusunan tugas akhir nomor B/402/PL1.R1/EP.00.08/2021 kelompok A1.

\section{REFERENSI}

[1] I. S. Roidah, "PEMANFAATAN LAHAN DENGAN MENGGUNAKAN SISTEM HIDROPONIK", bonoworo, vol. 1, no. 2, pp. 43-49, Jun. 2015.

[2] S. Wibowo, "Pengaruh Aplikasi Tiga Model Hidroponik DFT Terhadap Tanaman Pakcoy (Brassica rapa L.)," J. Keteknikan Pertan. Trop. Dan Biosist., vol. 8, no. 3, pp. 245-252, Dec. 2020.

[3] F. B. Akbar and M. A. Muslim, "Pengontrolan Nutrisi pada Sistem Tomat Hidroponik Menggunakan Kontroler PID,” Jurnal EECCIS, vol. 10, no. 1, p. 6, 2016.

[4] N. Insyani, M. R. Kirom, and A. Qurthobi, "Pengaruh Kontrol Nutrisi Dengan Menggunakan Proportional Integral Ziegler Nichols Terhadap Produksi Selada Dengan Teknik Hidroponik NFT," eProceedings of Engineering, vol. 7, no. 1, Apr. 2020.

[5] I. Kustanti, M. A. Muslim, and E. Yudaningtyas, "Pengendalian Kadar Keasaman (pH) Pada Sistem Hidroponik Stroberi Menggunakan Kontroler PID Berbasis Arduino Uno,” Jurnal Mahasiswa TEUB, vol. 2, no. 1, p. 6, 2014.

[6] D. Pancawati and A. Yulianto, "Implementasi Fuzzy Logic Controller untuk Mengatur Ph Nutrisi pada Sistem Hidroponik Nutrient Film Technique (NFT)," J. Nas. Tek. ELEKTRO, vol. 5, no. 2, Jul. 2016.

[7] A. R. Al Tahtawi and R. Kurniawan, "PH control for deep flow technique hydroponic IoT systems based on fuzzy logic controller," J. Teknol. Dan Sist. Komput., vol. 8, no. 4, pp. 323-329, Oct. 2020. 
[8] Sotyohadi, Wahyu Surya Dewa, and I Komang Somawirata, "Perancangan Pengatur Kandungan TDS dan PH pada Larutan Nutrisi Hidroponik Menggunakan Metode Fuzzy Logic,” ALINIER J. Artif. Intell. Appl., vol. 1, no. 1, pp. 33-43, Mar. 2020.

[9] M. N. R. Ibrahim, M. Solahudin, and S. Widodo, "Control System for Nutrient Solution of Nutrient Film Technique Using Fuzzy Logic,” TELKOMNIKA Telecommun. Comput. Electron. Control, vol. 13, no. 4, p. 1281, Dec. 2015.

[10] S. Mashumah, M. Rivai, and A. N. Irfansyah, "Nutrient Film Technique based Hydroponic System Using Fuzzy Logic Control," in 2018 International Seminar on Intelligent Technology and Its Applications (ISITIA), Bali, Indonesia, Aug. 2018, pp. 387-390.

[11] F. Suryatini, S. Pancono, S. B. Bhaskoro, and P. M. S. Muljono, "Sistem Kendali Nutrisi Hidroponik berbasis Fuzzy Logic berdasarkan Objek Tanam," ELKOMIKA J. Tek. Energi Elektr. Tek. Telekomun. Tek. Elektron., vol. 9, no. 2, p. 263, Apr. 2021.

[12] K. Setyohadi, I. Ibrahim, and R. Rahmadewi, "Automatic pH and Nutrition Control System for Spinach Hydroponic Plants Based on fuzzy logic,” JIWP, vol. 7, no. 1, pp.169-180, Jan. 2021. 
